\title{
Entre lutos e pandemias: uma revisão narrativa
}

\author{
Griefs and pandemics: narrative review
}

\author{
Marcella Ricardo da Silva Simonetti ${ }^{1}$, Giovanna da Conceição Gomes ${ }^{1}$, Karla Gomes Nunes ${ }^{1}$
}

1 - Universidade Católica de Minas Gerais - PUC, Betim, MG, Brasil

marcella.simonetti@sga.pucminas.br

Palavras-chave:

Luto; Pandemias; COVID-19.

\section{RESUMO}

Introdução: em uma pandemia milhares de pessoas sofrem o processo do luto, a perda do ente querido mobiliza significativamente o bem-estar levando, por vezes, o comprometimento da sua saúde mental de curto a longo prazo. O luto em pandemias pode influenciar toda a estrutura social epsíquica principalmente quando não há espaço para socialização e apoio emocional, já que há a instalação do distanciamento social, da interrupção dos habituais ritos da cultura ocidental e falta de protagonismo do luto devido a quebra de um vínculo próximo. Método: foi feito um levantamento bibliográfico do período de 2019 a 2021 nas bases de dados Bireme e EBSCO, sendo usados os descritores luto, enlutados, pandemia e covid-19 e as correspondentes em inglês e espanhol, sendo selecionados 25 artigos, que após leitura dos resumos foram reduzidos a 7, que abordavam diretamente o assunto do presente trabalho. Resultado e Discussão: os artigos demostraram que está incluído no processo de luto a complexidade e a subjetividade, assim como, a necessidade do tempo para uma reorganização interna do enlutado. Os rituais fúnebres tendem a amenizar a dor da perda, no entanto, em momentos em que esses rituais estão proibidos e mudanças intensas acontecem ao entorno do luto, torna-se importante pensar e discutir sobre a complicação desse sentimento de enlutamento bem como preparar o sistema de saúde para auxiliar as pessoas que desenvolverem o luto complicado. Conclusão: a pandemia de COVID-19 trouxe mudanças drásticas nas circunstâncias que cercam a morte e o luto, deixando milhões de pessoas em condições adversas para a elaboração da perda de seus entes queridos, isso tende a se tornar um problema de saúde pública ao longo dos próximos anos sendo, portanto, um assunto que deve ser discutitido com prioridade, principalmente levando-se em consideração as circuntâncias brasileiras em que temos um número avassalador de mortes e um governo pouco colaborativo e descuidado, além de poucas pesquisas ao entorno do tema.

\begin{abstract}
Introduction: in a pandemic, thousands of people suffer the grieving process. The loss of a loved one significantly mobilizes well-being, and sometimes leads to short- and long-term impairment of their mental health. Mourning in a pandemics can influence the entire social and psychic structure, especially when there is no space for socialization and emotional support, as there is the installation of social distancing, the interruption of the usual rites of Western culture and lack of protagonist in mourning due to the breakdown of a close bond. Method: a bibliographic survey was carried out from 2019 to 2021 in the Bireme, EBSCO and Lilacs databases, using the descriptors mourning, mourner, pandemic and covid-19 and the corresponding descriptors in Portuguese and Spanish, with 25 articles being selected. After reading of the abstracts, they were reduced to 7 articles that directly addressed the subject of the present study. Background and Results: the articles demonstrated that complexity and subjectivity are included in the grieving process, as well as the need for time for an internal reorganization of the mourner. Funeral rituals tend to ease the pain of loss, however, at times when these rituals are prohibited and intense changes take place around grief, it is important to think and discuss the complication of mourning as well as prepare the system to help people who develop complicated grief. Conclusion: the articles demonstrated that complexity and subjectivity are included in the grieving process, as well as the need for time for an internal reorganization of the mourner. Funeral rituals

Keywords: tend to ease the pain of loss, however, at times when these rituals are prohibited and intense changes Bereavements; take place around grief, it is important to think and discuss the complication of mourning as well as
\end{abstract} Pandemics; COVID-19. prepare the system to help people who develop complicated grief. 


\section{INTRODUÇÃO}

Em 11 de março de 2020, a doença causada pelo novo coronavírus (SARS-CoV-2) foi declarada como causadora de uma pandemia pela Organização Mundial da Saúde (OMS). Segundo os dados da mesma instituição $80 \%$ dos indivíduos infectados desenvolvem a formas leve ou moderada da infecção, $20 \%$ manifestam a versão severa e desses, cerca de $5 \%$ desenvolvem a forma mais grave, podendo evoluir rapidamente para um quadro de síndrome respiratória aguda grave e outras complicações que podem levar ao óbito.

Os dados divulgados pelo Ministério da Saúde Brasileiro, em 11 de maio de 2021, mostraram que o país contabiliza mais de 15 milhões de casos da doença e cerca de 423 mil mortes causadas por ela. ${ }^{2}$

A elevada taxa de transmissibilidade do novo coronavírus e o desleixo inicial do governo Brasileiro em relação a situação fez com que o aumento dos casos fosse exponencial chegando a seu pior estágio e levando os governos estaduais e municipais a declararem, além da situação de emergência sanitária e estado de calamidade decorrentes da pandemia, medidas administrativas excepcionais para o serviço funerários, inclusive com a abreviação ou interrupção de rituais tradicionais celebrados para homenagear os mortos e confortar os indivíduos enlutados. ${ }^{3}$

Estudos recentes nos mostram que tanto a pandemia quanto as medidas adotadas para contêla apresentam impactos diretos na saúde mental das pessoas, aumentando o risco para surgimento de sintomas de estresse, ansiedade e depressão, o que vem sendo identificado na população geral e em profissionais da saúde. ${ }^{4}$

Historicamente, as pandemias trazem consigo essa grande associação a perdas em massa, tanto de rotinas, conexões sociais, estabilidade financeira, quanto de vidas humanas. Milhares de pessoas têm vivenciado mudanças repentinas em todo seu contexto social, precisando lidar de imediato com a imprevisibilidade do futuro e, no meio de toda essa imersão no incerto podem perder alguém da sua rede socioafetiva em decorrência da doença de maneira bastante instantânea. ${ }^{3}$

Desde o início da pandemia, pudemos observar que várias foram as reformulações dos aspectos e experiências acerca do processo de morte e de seus rituais e isso é agravado pelo fato da cultura ocidental não ser preparada para vivenciar os processos de perda. O certo é que luto, morte e perda são assuntos que pouco se fala, mas em um contexto como o atual ganha uma importância ímpar. ${ }^{3}$

O luto, que tem etimologia latina (lucto) e significa sentimentos de extrema tristeza, angústia e saudades provocados pela perda de alguma coisa ou alguém importante, é um processo natural relacionado a uma quebra de vínculos. A Psicologia há muito tempo reconhece o valor emocional e o papel estruturante da vivência deste sentimento devido à sua extrema importância para ajudar na elaboração das perdas, portanto, o luto é normal, esperado e necessário. Diante disso, temos que o processo de luto não é patológico a priori, trata-se de uma resposta emocional esperada em uma situação de perda, é um direito de todas as pessoas, independente do grau de parentesco ou de afinidade com quem partiu. ${ }^{4}$

Os ritos de passagem relacionados à morte fazem parte do processo natural em várias culturas e são citados desde os primórdios da humanidade, sendo conceituados como "ações simbólicas, comportamentos repetitivos, padronizados e altamente valorizados, que auxiliam o indivíduo a canalizar emoções, compartilhar com seus pares suas crenças e transmitir seus valores"s de forma a marcar a transitoriedade da vida, permitindo que o enlutado confronte a perda concreta que sofreu e deflagre seu processo de luto, possibilitando a manifestação pública de seu pesar. ${ }^{5}$

A ausência desses rituais de despedida pode dificultar a concretização da perda. Ademais, as mortes que se dão de maneira brusca e inesperadas impossibilitam o preparo do enlutado para lidar com a situação, já que existe uma diferença significativa de temporalidade entre a morte física e a morte social e psíquica, tudo isso, gera um processo dificultoso de aceitação do luto. ${ }^{4}$

A pandemia do COVID-19 nos proporciona ambas as circunstâncias: proibição dos ritos de passagem e, por muitas vezes, a morte de pessoas de forma inesperada. Hoje, poucas pessoas são autorizadas a participar dos enterros de entes queridos, que ocorrem também sem o intervalo comum do velório, onde se encontra o conforto da presença de amigos e outros familiares. Em função disso, o presente artigo tem o escopo de realizar uma revisão narrativa analisando o processamento do luto alterado pela pandemia. 


\section{MÉTODO}

Iniciou-se uma busca de artigos científicos, publicados apenas em periódicos científicos, de abril de 2019 a abril de 2021 nas bases de dados da Bireme (MedLine, Lilacs, IBECS, SciELO) e da EBSCO (PsycInfo, PsycArticles, Psychology and Behaviral Sciences Collection, Academic Search Complete). Os descritores utilizados para pesquisa foram compostos por "grief" or "mourning" adicionados ao operador booleano (and) com um dos seguintes termos: "pandemic" e "coronavirus infections". Todas as quatro composições foram pesquisadas e os quatro descritores não foram pesquisados de forma isolada com os seus respectivos em inglês e espanhol.

Os critérios de inclusão foram ter as expressões utilizadas nas buscas no título ou palavras-chave e ter explícito no resumo que o texto se relaciona com luto associado a pandemia. Como também, ter como eixo principal a avaliação do luto em períodos de pandemia. Os critérios de exclusão foram não apresentar os critérios de inclusão e a duplicidade. Nessa pesquisa, não foram incluídas teses de mestrado ou doutorado. Assim, após essa condução, foi realizada a leitura completa dos sete artigos selecionados. Posteriormente, foram elaborados e apresentados os campos de discussão, resultados, metodologia e conclusão do campo.

\section{RESULTADOS E DISCUSSÃO}

O luto é um o processo caracterizado pelo rompimento de um vínculo significativo. Como citado anteriormente, a cultura ocidental não é, em sua grande parte, preparada para os processos de perda, portanto, a morte de alguém importante muda a percepção acerca da estabilidade, segurança e controle de um mundo presumido. ${ }^{3}$

No processo do luto a pessoa enlutada passar por um estado de recolhimento. Trata-se de uma trajetória complexa e subjetiva, durante a qual é comum que ela aparente sentimentos de tristeza, crises de choro, se recuse a sair de casa e perca o interesse em atividades que antes amava. Além disso, a pessoa também pode apresentar emoções que nem sempre são racionais, mas são inerentes ao processo vivenciado, como culpa, frustração, irritabilidade, desânimo, angústia, medo e desespero. ${ }^{5}$

Embora dolorosa, passar por essa experiencia é necessário, pois, nesse momento, o enlutado assimila e enfrenta o acontecimento, para então reconstruir sua vida. Segundo grande parte dos psicanalistas, a vivência do luto propicia que o enlutado se reorganize, e se restabeleça psiquicamente. ${ }^{3}$

Segundo a psiquiatra suíça-americana, Elisabeth Kübler-Ross ${ }^{5}$, o luto se apresenta em cinco estágios, sendo eles a negação - em que o sujeito tenta inconscientemente se proteger de uma verdade inconveniente; a raiva - nesse momento o enlutado pode apresentar condutas ríspidas e desagradáveis; a barganha ou negociação - em que o enlutado negocia consigo mesmo ou com a entidade superior em que acredita na tentativa desesperada de aliviar a sua dor; a depressão - em que a pessoa se apega à dor causada pela partida do ente querido e, por fim a aceitação, em que o enlutado consegue conviver pacificamente com a perda. ${ }^{5}$

Obviamente as cinco fases do luto não são vividas linearmente, cada indivíduo enlutado passa por essa experiência de modo singular, de acordo com as suas competências emocionais e história de vida. ${ }^{6}$

Sabidamente, os ritos fúnebres tem propósitos tanto psicológicos quanto sociais, isso porque, na medida em que os enlutados demonstram os sentimentos de pesar diante de um grupo eles conseguem de certa forma assimilar alguns dos estágios do luto, reconhecendo a realidade da perda, processando a dor do luto com apoio emocional das pessoas ali presentes, e reconhecendo a necessidade de novos ajustes para o mundo, isso faz com que a pessoa se sinta mais apoiada pela sociedade ao seu redor, compartilhe de seus sentimentos e passe pelo processo de luto de maneira mais fácil. ${ }^{6}$

Importa mencionar que, há poucos estudos que comprovem que a execução de funerais ajuda na superação do luto, principalmente na sociedade Brasileira, mas os estudos norte-americanos e europeus abordados na presente revisão, sugerem de maneira enfática que a sua realização auxilia na restauração de sentimentos negativos devido à expressão de sentimentos e emoções, além da aceitação mais fácil da perda do ente através da criação de um vínculo emblemático. ${ }^{6}$

Em março de 2020, com o início da pandemia de COVID-19, o Brasil foi tomado por uma sensação de instabilidade emocional e medo, isso fez com que as pessoas apresentassem manifestações físicas e psíquicas inerentes a uma percepção repentina de um processo de ruptura com vida anterior, em outras palavras, o mundo experimenta um estado de 
fragilidade psicológica. Como se não bastasse essa ruptura com a vida anterior, um cenário pandêmico costuma ocasionar mortes em números elevados num pequeno espaço de tempo e, em especial, nessa pandemia, como medida para conter a rápida proliferação do número de infectados, o mundo experimentou pela primeira vez a interrupção dos seus ritos fúnebres. ${ }^{6}$

Segundo Maria Júlia Kóvacs, em situações de desastres e emergências, como a que estamos inseridos, a chamada "morte escancarada" (que são mortes coletivas, anônimas e com corpos mutilados, dificultando o processo de despedida) se faz presente, trata-se de uma morte violenta, que invade a vida das pessoas inesperadamente de maneira descuidada, provocando exposição, banalização e vulnerabilidades e como consequência, o processo de elaboração do luto pode ser prejudicado. ${ }^{7}$

Os desastres e emergências são eventos que aumentam a vulnerabilidade e desamparo dos indivíduos e, portanto, favorecem o que chamamos de luto complicado, conceituado como aquele em que o enlutado se fixa em um dois estágio, como por exemplo a negação ou a depressão. ${ }^{7}$

Os pontos considerados complicadores do luto são, principalmente as perdas múltiplas, mortes repentinas, exposição à mídia, falta de suporte, corpos desfigurados, ausência de corpo e impossibilidade de rituais como velório e enterro. ${ }^{4}$ Veja, que na pandemia da COVID-19 temos pelo menos três desses complicadores presentes no cotidiano das mortes que se dão em virtude do vírus, isso porque, geralmente temos pessoas em bom estado geral que após se infectarem apresentam um quadro de piora muito rápido e, portanto, a morte dessas pessoas é inesperada e repentina, além disso devido a superlotação dos serviços brasileiros, a equipe de saúde não consegue dar o suporte esperado aos familiares nesse momento e os ritos fúnebres estão proibidos devido à questões sanitárias na maioria dos municípios. ${ }^{8}$

$\mathrm{O}$ desenrolar desta pandemia colocou o luto em um lugar de protagonismo. Geralmente, aspectos paliativos e de cuidado são sempre colocados a margem em detrimento de novas descobertas quanto a fisiopatologia da doença e seus tratamentos, no entanto, nesse momento não se sabe muito em termos científicos, não se tem um tratamento eficaz precoce, não se tem certeza sobre o que fazer e o que seria melhor para o paciente e, por consequência, nos deparamos com o sentimento de impotência e a necessidade de aceitação. Diante dessa nova realidade, o atual estresse emocional vivenciado pelas pessoas em meio a pandemia cria um ambiente propício e potencial para o favorecimento e emergência de distúrbios psicológicos. ${ }^{8}$

\section{CONCLUSÃO}

Considerando a emergência do novo coronavírus, os seus impactos, como exposto, são diretamente perceptíveis. Atualmente, diante do número crescente de mortes e consequentemente de enlutados, da alteração dos rituais post mortem, nota-se que já se há ciência do aumento de estresse, ansiedade e depressão. ${ }^{2}$ Como também, as emoções muitas vezes não conscientes de culpa, frustração, irritabilidade, desânimo, angústia, medo e desespero mais presentes, as quais, se banalizadas, podem complicar o estado de saúde do enlutado. ${ }^{5}$ Assim, nota-se que a condução das perdas na pandemia está imersa em estruturas complexas de mudanças biopsicossociais mais amplificadas.

No presente artigo, identificou-se como de grande importância, para os enlutados que enfrentam esse rompimento de vínculo significativo, as fases não lineares de negação, raiva, barganha/negociação, depressão e aceitação. Os sentimentos vinculados envolvem o reconhecimento da partida do ente querido e a dor do luto que tem o apoio emocional como facilitador. Em grande parte, com a pandemia, o apoio emocional institucional, comunitário e familiar, assim como os espaços de encontro e as práticas de despedida dos mortos foram inibidos, os quais ajudavam na recomposição da fragilidade psicológica envolvida no luto. Nesse contexto, cabe perceber o luto como um processo importante, reconhecendo a influência dele em vida. Nesse sentido, o apoio dos profissionais de saúde pode ser necessário para que os enlutados sobrevivam aos sentimentos difíceis. Para amenizá-los é essencial a não banalização e o acolhimento que permita dar espaço e escuta, se necessário, aos sentimentos intrínsecos do luto.

Podemos, portanto, prever que o transtorno de luto complicado tem o potencial de se tornar um problema de saúde pública que exigirá uma resposta dos serviços de saúde e equipamentos sociais, além de preparo profissional para tal, o que não está sendo pensado pelo Governo Brasileiro nesse momento, que apresenta mais um aspecto negacionista da real situação, tomando medidas como o corte de verbas 
para pesquisas justamente em um momento em que elas são fundamentais.

\section{REFERÊNCIAS}

1. Rosalmeida DC, Azevedo RCS, Vieira LC, Côrtes MTF, Federmann ALP, Cucco LM, Rodrigues LR, Domingues JFR, Dantas JE, Portella IP, Cassorla RMS. O luto nos tempos da COVID-19: desafios do cuidado durante a pandemia. Rev Latinoam Psicopatol Fundam 2020;23(3):509-33. doi: https:// doi.org/10.1590/1415-4714.2020v23n3p509.5

2. Crepaldi MA, Schmidt B, Noal DS, Bolze DAS, Gabarra LM. Terminalidade, morte e luto na pandemia de COVID-19: demandas psicológicas emergentes e implicações práticas. Estud Psicol 2020;37:e200090. doi: https://doi.org/10.1590/1982$0275202037 \mathrm{e} 200090$

3. Petry SE, Hughes D, Galanos A. Grief: The Epidemic Within an Epidemic. Am J Hosp Palliat Care 2021;38(4):419-22. doi: https://doi.org/10.1177/1049909120978796

4. Boland MJ. A hard time to die: grief and the coronavirus: Michael Boland. Br J Gen Pract. 2020 Jun 25;70(696):343. doi: https://doi.org/10.3399/bjgp20X710513

5. Corpuz JCG. From grieving to healing: moving forward a year after COVID-19. J Public Health 2021;43(2):e403-e404. doi: https://doi.org/10.1093/pubmed/fdab099

6. Wallace CL, Wladkowski SP, Gibson A, White P. Grief During the COVID-19 Pandemic: Considerations for Palliative Care Providers. J Pain Symptom Manage. 2020 Jul;60(1):e70-e76. doi: https://doi.org/10.1016/j.jpainsymman.2020.04.012

7. Kovács MJ. Educação para a morte. desafios na formação dos profissionais de saúde e educação. São Paulo, Casa do Psicólogo, 2003.

8. Verztman J, Romão-Dias D. Catástrofe, luto e esperança: o trabalho psicanalítico na pandemia de COVID-19. Rev Latinoam Psicopatol Fundam 2020;23(2):269-90. doi: https:// doi.org/10.1590/1415-4714.2020v23n2p269.7 